https://doi.org/10.46813/2020-130-069

\title{
GAS DISCHARGE IN PLASMA-METAL WAVEGUIDE WITH VARYING RADIUS OF METAL ENCLOSURE PARTIALLY FILLED BY RADIALLY NON-UNIFORM MAGNETIZED PLASMA
}

\author{
N.A. Azarenkov, V.P. Olefir, A.E. Sporov \\ V.N. Karazin Kharkiv National University, Kharkiv, Ukraine \\ E-mail: sporov@karazin.ua,vpolefir@karazin.ua
}

\begin{abstract}
The article presents the results of theoretical study of phase and attenuation characteristics of the symmetric electromagnetic wave in long waveguide structure that partially filled by radially non-uniform plasma immersed in external steady magnetic field. The results of theoretical study of stationary gas discharge sustained by this wave in the considered waveguide structure with slightly varying radius of metal enclosure in the framework of electrodynamic model are presented as well. It was studied the influence of the effective plasma collision frequency on the phase and attenuation wave properties and on the plasma density axial distribution in gas discharge considered for different radial plasma density profiles.
\end{abstract}

PACS: 52.35-g, 52.50.Dg

\section{INTRODUCTION}

Till now the intensive theoretical and experimental studies of plasma sources with the specified plasma parameters are carried out in different laboratories over the world $[1,2]$. One of the possible kind of plasma sources are the microwave gas discharges in rather long and narrow tubes that are sustained by the eigen waves of the discharge structure. This is the characteristic feature of such discharges that is used in modeling of stationary plasma density axial distribution in the framework electrodynamic approach [2]. Such modeling consists of the detailed description of wave propagation and attenuation, and using the model equation for the description the discharge features $[2,3]$.

The plasma - metal waveguides with slightly varying radius of metal enclosure along the discharge are used as a chambers for gas discharges [4]. In the previous studies it was carried out the investigation of axial structure of gas discharge in such waveguides under the assumption of radially uniform magnetized plasma [5]. But usually in such discharges plasma density is strongly non-uniform in radial direction. The aim of this work is to study influence of variable radius of metal waveguide and plasma density radial profile on the properties of the discharge that is sustained by the symmetric wave which is promising for gas discharge sustaining $[1,2]$.

\section{BASIC EQUATIONS}

Let us consider the model of the stationary stage of gas discharge in diffusion controlled regime that sustains by the symmetric electromagnetic wave in rather long magnetized plasma-metal waveguide structure with variable radius of metal enclosure in the framework of electromagnetic approach. The considered electromagnetic symmetric wave propagates along three component waveguide structure that is composed of the plasma column with radius $R_{p}$, vacuum region $R_{p}<r<R$ and cylindrical metal enclosure of radius $R$. External steady magnetic field $\vec{B}_{0}=\left(0,0, B_{0}\right)$ is directed along the axis of the structure. Plasma was considered in the hydrodynamic approach as a cold, weakly absorbing media with constant effective collisional frequency $\tilde{v}$ ISSN 1562-6016. BAHT. 2020. №6(130)

PROBLEMS OF ATOMIC SCIENCE AND TECHNOLOGY. 2020, № 6. Series: Plasma Physics (26), p. 69-73. that is considered to be small compared to the given wave frequency and is constant in axial and radial directions [6]. The case when only one mode with the specified azimuthal wave number is excited in the discharge structure is considered. It was supposed that all geometric, plasma and wave parameters slightly vary in axial direction on the distances of wavelength order, so the WKB approach can be used to obtain the solution of the system of Maxwell equations [7]. This solution can be found in the form:

$$
E, H_{r, \varphi, z}(r, \varphi, z)=E, H_{r, \varphi, z}(r, z) \mathrm{e}^{-i \omega t+\int_{0}^{z} k_{3}\left(z^{\prime}\right) d z^{\prime}}
$$

where $\omega$ is the wave frequency; $k_{3}$ is the axial wavenumber, $E, H-$ amplitude of electric and magnetic wave fields, respectively. It was considered the case when the variation variable $A$ value along the discharge at the distances of the order of wavelength is small as compared with the magnitude of this variable, therefore $A^{-1} \frac{\partial A}{\partial z}<<k_{3}$, where symbol $A$ denotes $E, H, k_{3}$, or $n$. Thus, in further description all terms of order $O\left(\frac{1}{k_{3}} \frac{\partial}{\partial z} \ln (A)\right)$ were neglected [7].

It was also considered that radial plasma density distribution can be expressed in the Bessel-like form as: $n(r)=n(0) J_{0}(\delta r)$. Here $J_{0}$ is the Bessel function of the first kind and $\delta$ is plasma density non-uniformity parameter, that varies from $\delta=0$ (radially uniform plasma) up to $\delta=2.405$ (strong radially non-uniform plasma that corresponds to ambipolar diffusion regime). In such case one can obtain the equations for radial wave components in plasma region have the following form:

$$
\left\{\begin{array}{l}
H_{r}^{p}(r)=-\frac{k_{3}}{k} E_{\varphi}^{p}(r) \\
E_{z}^{p}(r)=\frac{k_{3}}{k \varepsilon_{1}(r)} H_{\varphi}^{p}(r)-\frac{i \varepsilon_{2}(r)}{\varepsilon_{1}(r)} E_{\varphi}^{p}(r),
\end{array}\right.
$$


where $\varepsilon_{1,2,3}(r)$ are the components of permittivity tensor of magnetized collisional plasma [6] that depends on radial coordinate $r$ throw the dependence of $n(r)$. The ordinary differential equations for other wave field components in plasma region can be written as:

$$
\left\{\begin{array}{l}
\frac{d E_{z}^{p}}{d r}=\frac{k_{3} \varepsilon_{2}(r)}{\varepsilon_{1}(r)} E_{\varphi}^{p}(r)+i \frac{k_{3}^{2}-k^{2} \varepsilon_{1}(r)}{k \varepsilon_{1}(r)} H_{\varphi}^{p}(r) \\
\frac{d E_{\varphi}^{p}}{d r}=-\frac{1}{r} E_{\varphi}^{p}(r)+i k H_{z}^{p}(r) \\
\frac{d H_{z}^{p}}{d r}=\frac{k_{3} \varepsilon_{2}(r)}{\varepsilon_{1}(r)} H_{\varphi}^{p}(r)-i \frac{p(r)}{k \varepsilon_{1}(r)} E_{\varphi}^{p}(r) \\
\frac{d H_{\varphi}^{p}}{d r}=-\frac{1}{r} H_{\varphi}^{p}(r)-i k \varepsilon_{3}(r) E_{z}^{p}(r),
\end{array}\right.
$$

where $p(r)=\varepsilon_{1}(r)\left(k_{3}^{2}-k^{2} \varepsilon_{1}(r)\right)+k^{2} \varepsilon_{2}^{2}(r), k=\omega / c-$ is the vacuum wavenumber.

The expressions for wave field components in vacuum region can be written as:

$$
\left\{\begin{array}{l}
E_{z}(r)=A_{1} I_{0}(\kappa r)-A_{2} K_{0}(\kappa r) \\
E_{\varphi}(r)=\frac{i k A_{3} I_{0}^{\prime}(\kappa r)}{\kappa}+\frac{i k A_{4} K_{0}^{\prime}(\kappa r)}{\kappa} \\
E_{r}(r)=-\frac{i k_{3} A_{1} I_{0}^{\prime}(\kappa r)}{\kappa}-\frac{i k_{3} A_{2} K_{0}^{\prime}(\kappa r)}{\kappa} \\
H_{z}(r)=A_{3} I_{0}(\kappa r)-A_{4} K_{0}(\kappa r) \\
H_{\varphi}(r)=\frac{i k A_{1} I_{0}^{\prime}(\kappa r)}{\kappa}+\frac{i k A_{2} K_{0}^{\prime}(\kappa r)}{\kappa} \\
H_{r}(r)=-\frac{i k_{3} A_{3} I_{0}^{\prime}(\kappa r)}{\kappa}-\frac{i k_{3} A_{4} K_{0}^{\prime}(\kappa r)}{\kappa},
\end{array}\right.
$$

where $\kappa^{2}=k_{3}^{2}-k^{2}$ is the transverse wave number in vacuum and $A_{1-4}$ are field constants that can be obtained from the boundary conditions and a stroke denotes derivative by argument.

Taking into account boundary conditions on the plasma - vacuum interface (the continuity of tangential wave field components at $r=R_{p}$ ) it is possible to obtain such expressions for field constants $A_{1-4}$ :

$$
\left\{\begin{array}{l}
A_{1}=\kappa R_{p} K_{1}\left(\kappa R_{p}\right) E_{z}^{P}\left(R_{p}\right)+i \frac{\kappa^{2} R_{p} K_{0}\left(\kappa R_{p}\right)}{k} H_{\varphi}^{P}\left(R_{p}\right) \\
A_{2}=\kappa R_{p} I_{1}\left(\kappa R_{p}\right) E_{z}^{P}\left(R_{p}\right)-i \frac{\kappa^{2} R_{p} I_{0}\left(\kappa R_{p}\right)}{k} H_{\varphi}^{P}\left(R_{p}\right) \\
A_{3}=\kappa R_{p} K_{1}\left(\kappa R_{p}\right) H_{z}^{P}\left(R_{p}\right)-i \frac{\kappa^{2} R_{p} K_{0}\left(\kappa R_{p}\right)}{k} E_{\varphi}^{P}\left(R_{p}\right) \\
A_{4}=\kappa R_{p} I_{1}\left(\kappa R_{p}\right) H_{z}^{P}\left(R_{p}\right)+i \frac{\kappa^{2} R_{p} I_{0}\left(\kappa R_{p}\right)}{k} E_{\varphi}^{P}\left(R_{p}\right) .
\end{array}\right.
$$

In these formulas it is supposed that the expressions for wave field components at plasma-vacuum interface $E^{p}\left(R_{p}\right), H^{p}\left(R_{p}\right)$ are obtained with the help of numerical integration of the system of ordinary differential equations (3).

The final equation (local dispersion equation) can be obtained from the boundary conditions at vacuum metal interface (the vanishing of the wave tangential components at $r=R)$ :

$$
\left\{\begin{array}{l}
A_{1} I_{0}(\kappa R)+A_{2} K_{0}(\kappa R)=0 \\
A_{3} I_{1}(\kappa R)-A_{4} K_{1}(\kappa R)=0 .
\end{array}\right.
$$

The solution of the local dispersion equation (6) connects the values of local density $n$ and complex axial wave vector $k_{3}$ at the given wave frequency value $\omega$. So, from this equation (6) it is possible to obtain the dependence of attenuation coefficient $\alpha=\operatorname{Im}\left(k_{3}\right)$ upon the plasma density $n$. This dependence can be used to determine the density axial gradient $d n / d z$ for the discharges in the diffusion controlled regime from the relation $[2,3]$ :

$$
\frac{d n}{d z}=-\frac{2 n \alpha}{1-\frac{n}{\alpha} \frac{d \alpha}{d n}}
$$

The axial plasma density profile $n(z)$ in gas discharge sustained by the symmetric wave in the considered waveguide structure in diffusion controlled regime can be obtained as a result of numerical integration of the ordinary differential equation (7).

It is necessary to mention that surface wave can sustain the stable discharge in the diffusion controlled regime only when the Zakrzewski's stability condition is fulfilled [8]:

$$
\frac{d}{d n} \frac{|\alpha|}{n}<0
$$

It is necessary to check the fulfillment of this criterion (8) when solving the ordinary differential equation (7).

\section{MAIN RESULTS}

The electromagnetic wave that sustains the discharge is the eigen wave of the discharge structure on the whole length of the plasma column. So, the ability of gas discharge sustaining by this wave is mainly determined by the electrodynamic properties of the wave considered. Because of that, the study consists of two stages: 1) the detailed investigation of the phase and attenuation properties of the wave; 2) the study of the axial structure of gas discharge sustained by the wave considered at stage 1 .

The studied wave possesses all six components of electric and magnetic wave field, so the determination of wave field components in plasma region (the solution of system (3)) for arbitrary problem parameters is possible only with the help of numerical methods. To carry out the study the following dimensionless variables and parameters were introduced: wave frequency $\mu=\omega / \omega_{p}$, axial wave number $x=\operatorname{Re}\left(k_{3}\right) R_{p}$, attenuation coefficient $\alpha=\operatorname{Im}\left(k_{3}\right) R_{p}$, effective collision frequency $v=\tilde{v} \omega^{-1}$, external magnetic field value $\Omega=\omega_{C e} / \omega$, radius of plasma column $\sigma=R \omega / c$, radius of metal enclosure $\eta=R / R_{p}$, axial coordinate $\xi=\tilde{v} z / \omega / R_{p}$.

At first, the influence of the collision frequency $v$ on phase and attenuation properties of the symmetric wave was studied for the case of radially uniform plasma. In the case considered the local dispersion equation (6) has one solution for the problem parameters set. The obtained solutions are presented on the Fig. 1 (dimensionless frequency via axial wave number) and 
on the Fig. 2 (attenuation coefficient via axial wave number).

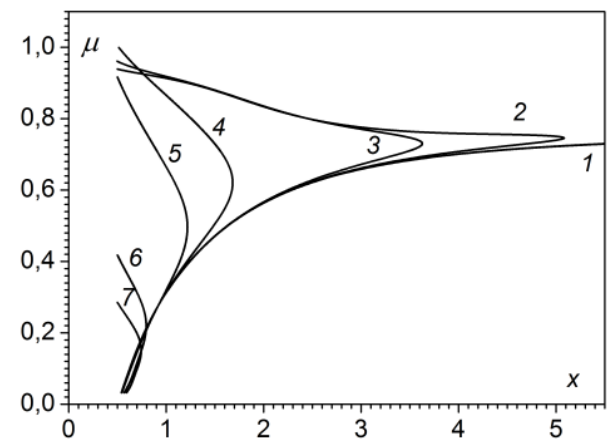

Fig. 1. The dependence of dimensionless eigen wave frequency $\mu$ via the dimensionless wave number $x$ for different $v$ values. Problem parameters are the following: $\Omega=0.6, \sigma=0.5, \eta=1.5, \delta=0$. Numbers just near the curves correspond to different $v$ values: $1-v=0.005 ; 2-v=0.05 ; 3-v=0.1 ; 4-v=0.5$;

$$
5-v=1.0 ; 6-v=5.0 ; 7-v=10.0
$$

These solutions were obtained for the low collisional ( $v \ll 1.0$, curve 1), moderate collisional $(v \sim 1.0$, curves 2-5) and strong collisional ( $v>1.0$, curves 6,7$)$ regimes. It was obtained that the wave considered has difference behavior and regions of existence for different collisional frequency $v$ values. The greater the $v$, the shorter is the normalized frequency $\mu=\omega / \omega_{p}$ region of the wave existence. Also the maximum possible normalized frequency of this wave decreased with the increasing of $v$.

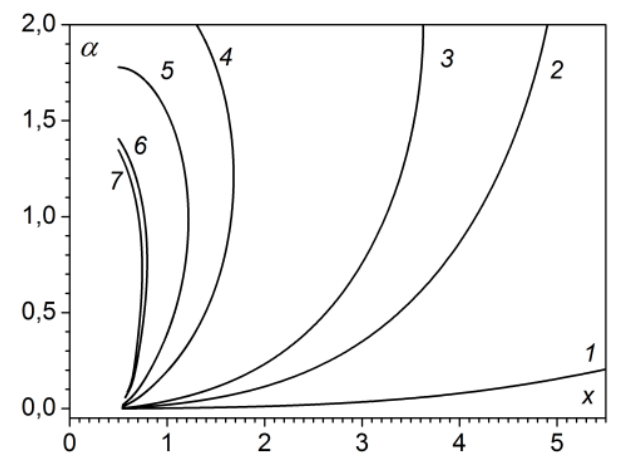

Fig. 2. The dependence of dimensionless attenuation coefficient $\alpha$ on the dimensionless wave number $x$ for different $v$ values. Problem parameters and curve numbering are the same as for the Fig. 1

The influence of the effective electron collision frequency $v$ on the spatial attenuation coefficient $\alpha=\operatorname{Im}\left(k_{3}\right) R$ was also studied. The results of the study are presented on the (see Fig. 2). It was obtained that the increase of the effective collision frequency value $v$ leads to the substantially increase of the wave attenuation coefficient. It is necessary to mention that the value of collision frequency have some different influence on the wave attenuation in the region of small, moderate and strong $v$ values.

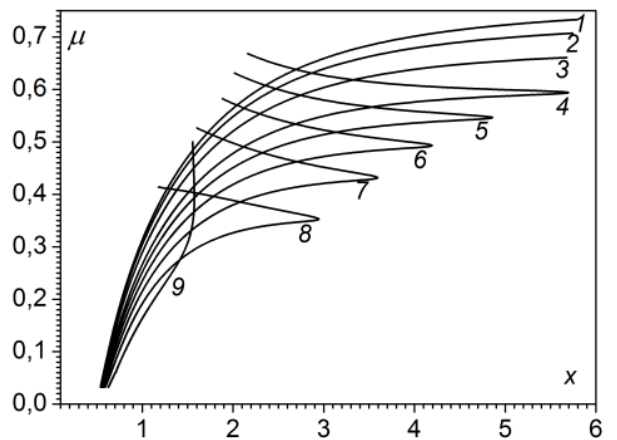

Fig. 3. The dependence of dimensionless eigen wave frequency $\mu$ via the dimensionless wave number $x$ for different non-uniformity parameter values $\delta$. Problem parameters are the following: $\Omega=0.6, \sigma=0.5, \eta=1.5$, $v=0.001$. Numbers just near the curves correspond to different $\delta$ values: $1-\delta=0 ; 2-\delta=0.6 ; 3-\delta=1.0$; $4-\delta=1.4 ; 5-\delta=1.6 ; 6-\delta=1.8 ; 7-\delta=2.0$; $8-\delta=2.2 ; 9-\delta=2.4$

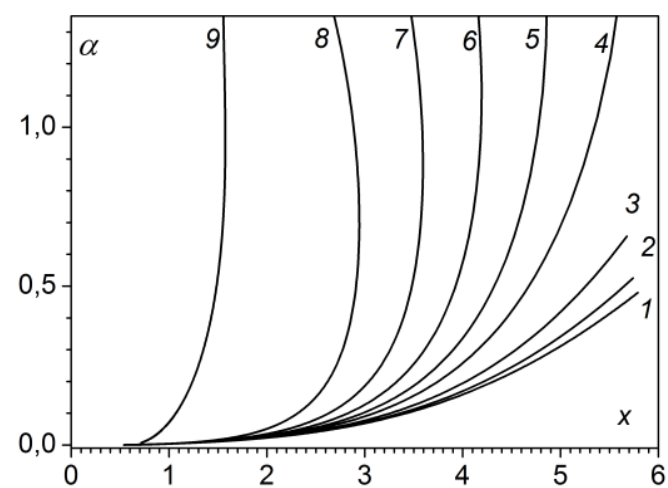

Fig. 4. The dependence of dimensionless attenuation coefficient $\alpha$ on the dimensionless wave number $x$ for different $\delta$ values. Problem parameters and curve numbering are the same as for Fig. 3

The influence of plasma density non-uniformity on the phase and attenuation properties at gradually increasing non-uniform parameter value $\delta$ from 0 up to 2.4 is studied. The numerical results of the influence of non-uniformity parameter $\delta$ on the normalized wave frequency $\mu=\omega / \omega_{p}$ are presented on the Fig. 3. It is shown that the dispersion has different behavior in the case of uniform and slightly non-uniform (curves 1-3), moderate (curves 4-8) and strong non-uniform plasma (curve 9). Generally, for the non-uniform plasma the increase of the non-uniformity parameter $\delta$ leads to the decrease of the symmetric wave phase velocity $V_{p h}=\mu / x$ for the fixed $x$ value.

The results of studying the influence of radial plasma density non-uniformity on the wave attenuation coefficient $\alpha$ are presented on the Fig. 4. The gradual increasing on plasma density radial non-uniformity parameter leads to substantial increasing on attenuation coefficient $\alpha$ (see curves 1-9 in Fig. 4). 


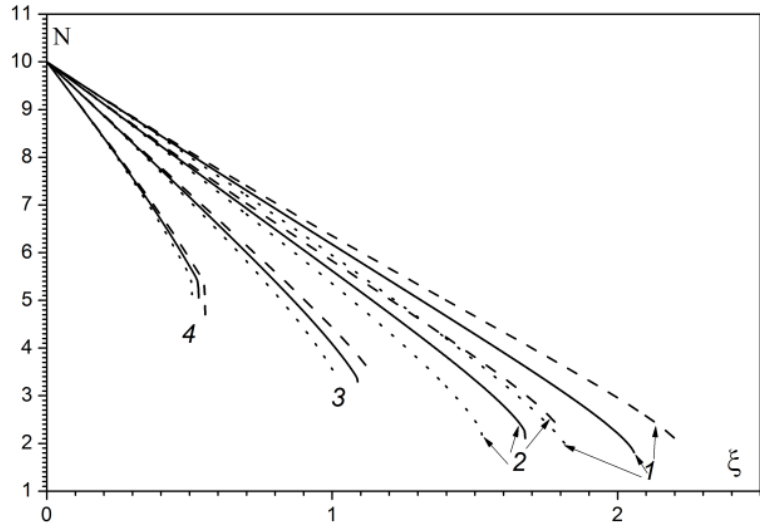

Fig. 5. The axial distribution on dimensionless plasma density $N=\omega_{p}{ }^{2} / \omega^{2}$ along the discharge via the dimensionless axial coordinate $\xi$ for different nonuniformity values $\delta$. Problem parameters are the following: $\Omega=0.6, \sigma=0.5, \eta=1.5, v=0.01$. Numbers just near the curves correspond to different $\delta$ values: $1-\delta=0 ; 2-\delta=1.0 ; 3-\delta=1.6 ; 4-\delta=2.0$. Solid line corresponds to the constant, dashed line - to the increasing and dotted line - to the decreasing radius of waveguide metal wall along the discharge

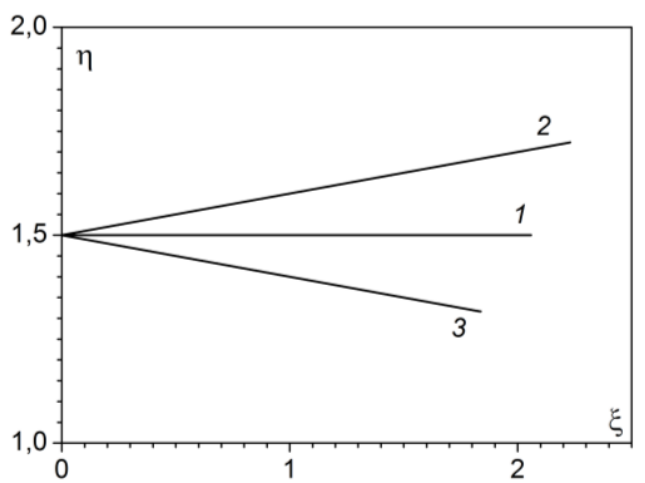

Fig. 6. The axial variation of dimensionless waveguide metal radius (parameter $\eta$ ) along the discharge via the dimensionless axial coordinate $\xi$. Numbers just near the curves corresponds: 1 - to the constant, 2 - to the increasing and 3 - to the decreasing radius of waveguide metal wall along the discharge

The results of numerical solution of the equation (7) to obtain plasma density axial distribution in the discharge sustained by symmetric waves are represented in Fig. 5. The Fig. 6 presents the appropriate lows of metal enclosure variation. Numbers on the curves 1,2 , 3,4 corresponds to the case of $\delta=0,1.0,1.6,2.0$, respectively. The results are presented for three cases of parameter $\eta$ varying along the discharge: constant $\eta$ value along the discharge - solid line in Fig. 5 (see curve 1 in Fig. 6); increasing $\eta$ value along the discharge - dashed line in Fig. 5 (see curve 2 in Fig. 6); and decreasing $\eta$ value along the discharge - dotted line in Fig. 5 (see curve 3 in Fig. 6).

The increase of non-uniformity parameter $\delta$ leads to the growth of the axial gradients of plasma density distributions and to the decrease of gas discharge normalized length $\xi_{\max }=\tilde{v} z_{\max } / \omega / R_{p}$. It was also obtained that the maximum possible value of the plasma density, that can be obtained in such discharges also increased with the increase of the parameter $\delta$ (see the dependence of normalized values of $\mu=\omega / \omega_{p}=1 / \operatorname{sqrt}(N)$ for different $\delta$ values in Fig. 3). It is shown that the influence of metal enclosure varying radius is much smaller for the case of strong radially non-uniformity that in the case of radially uniform plasma [5].

The decrease of the discharge length with the increase of the plasma density non-uniformity parameter $\delta$ can be explained due to the substantial increase of the attenuation coefficient $\alpha$ (see Fig. 4). Such behavior of $\alpha$ via $\delta$ is caused by the increased Joule heat losses due to the increase of the wave field strength under plasma density non-uniformity parameter growth.

\section{CONCLUSIONS}

It was studied the influence of slightly varying radius of metal enclosure and strong plasma density radial non-uniformity on the phase and attenuation properties of electromagnetic symmetric wave in three component waveguide structure partially filled by collisional, radially non-uniform magnetized plasma. The axial structure of gas discharge sustained by this wave for different values of effective collisional frequency and plasma density radial profiles was studied also. It was shown that the influence of variable radius of waveguide metal enclosure in the case of radially nonuniform plasma on the axial plasma density profile in the considered discharge is similar to the case of radially uniform plasma. But it is necessary to mention that this influence becomes much smaller with the increase of plasma non-uniformity parameter $\delta$.

This work was supported by the Ministry of Education and Science of Ukraine, under the grant $0118 \mathrm{U} 002023$

\section{REFERENCES}

1. I. Zhelyazkov, V. Atanassov. Axial structure of low-pressure high-frequency discharges sustained by travelling electromagnetic surface waves // Physics Reports. 1995, v. 255, № 2-3, p. 79-201.

2. H. Schlüter, A. Shivarova. Travelling-wavesustained discharges // Physics Reports. 2007, v. 443, № 4-6, p. 121-255.

3. C.M. Ferreira. Modelling of a low-pressure plasma column sustained by a surface wave // J. of Phys. D: Appl. Phys. 1983, v. 16, № 9, p. 1673-1685.

4. J. Wolinska-Szatkowska. Surface wave discharge in a conical tube // J. of Phys. D: Appl. Phys. 1987, v. 20, p. 977-978.

5. N.A. Azarenkov, V.P. Olefir, A.E. Sporov. Electromagnetic model of gas discharge in long tube of slightly varying radius // Problems of Atomic Science and Technology. Series «Plasma Physics» (25). 2018, № 6, p. 113-116.

6. A.N. Kondratenko. Surface and volume waves in bounded plasma. Moscow: "Energoatomizdat", 1985.

7. G.G. Lister, T.R. Robinson. Strongly damped surface waves in plasmas. I. The WKB approximation // J. of Phys. D: Appl. Phys. 1991, v. 24, № 11, p. 19931999. 
8. M. Moisan, Z. Zakrzewski. Plasma sources based on the propagation of electromagnetic surface waves //
J. of Phys. D: Appl. Phys. 1991, v. 24, № 7, p. 10251048.

\title{
ГАЗОВЫЙ РАЗРЯД В ПЛАЗМЕННО-МЕТАЛЛИЧЕСКОМ ВОЛНОВОДЕ С ИЗМЕНЯЮЩИМСЯ РАДИУСОМ МЕТАЛЛИЧЕСКОЙ СТЕНКИ, ЧАСТИЧНО ЗАПОЛНЕННОМ РАДИАЛЬНО НЕОДНОРОДНОЙ МАГНИТНО-АКТИВНОЙ ПЛАЗМОЙ
}

\author{
Н.А. Азаренков, В.П. Олефир, А.Е. Споров
}

Представлены результаты теоретического исследования фазовых свойств и пространственного затухания симметричной электромагнитной волны в длинной волноводной плазменно-металлической структуре, частично заполненной радиально-неоднородной плазмой, помещенной во внешнее аксиальное постоянное магнитное поле. Представлены результаты теоретического исследования аксиального распределения плотности плазмы в стационарном газовом разряде, поддерживаемом симметричной волной, в рассматриваемой волноводной структуре, полученные в рамках электродинамической модели разряда. Исследованы также влияния эффективной частоты столкновений электронов плазмы на фазовые свойства и пространственное затухание волны, а также на аксиальное распределение плотности плазмы в газовых разрядах, поддерживаемых этой волной, для различных радиальных профилей плотности плазмы.

\section{ГАЗОВИЙ РОЗРЯД У ПЛАЗМОВО-МЕТАЛЕВОМУ ХВИЛЕВОДІ ЗІ ЗМІННИМ РАДІУСОМ МЕТАЛЕВОЇ СТІНКИ, ЧАСТКОВО ЗАПОВНЕНОМУ РАДІАЛЬНО-НЕОДНОРІДНОЮ МАГНІТНО-АКТИВНОЮ ПЛАЗМОЮ}

\section{М.О. Азарєнков, В.П. Олефір, О.С. Споров}

Представлено результати теоретичного дослідження фазових характеристик та просторового загасання симетричної електромагнітної хвилі в довгій хвилеводній плазмово-металевій структурі, що частково заповнена радіально-неоднорідною плазмою, яка знаходиться у зовнішньому аксіальному постійному магнітному полі. В межах електродинамічної моделі стаціонарного газового розряду отримано аксіальний розподіл густини плазми, що підтримується власною симетричною хвилею структури. Досліджено також впливи ефективної частоти зіткнень електронів плазми на фазові характеристики та просторове загасання хвилі, а також на аксіальний розподіл густини плазми в газових розрядах, що підтримуються нею, за різних радіальних розподілів густини плазми. 